\title{
Prevalence of resistance associated polymorphisms in Plasmodium falciparum field isolates from southern Pakistan
}

\author{
Najia Karim Ghanchi ${ }^{1 \dagger}$, Johan Ursing ${ }^{2 * \dagger}$, Mohammad A Beg ${ }^{1}$, Maria I Veiga ${ }^{2,3}$, Sana Jafri ${ }^{1}$, Andreas Mårtensson ${ }^{2,4}$
}

\begin{abstract}
Background: Scarce data are available on Plasmodium falciparum anti-malarial drug resistance in Pakistan. The aim of this study was, therefore, to determine the prevalence of $P$. falciparum resistance associated polymorphisms in field isolates from southern Pakistan.

Methods: Blood samples from 244 patients with blood-slide confirmed P. falciparum mono-infections were collected between 2005-2007. Single nucleotide polymorphisms in the $P$. falciparum chloroquine resistance transporter (pfcrt K76T), multi drug resistance (pfmdr1 N86Y), dihydrofolate reductase (pfdhfr A16V, N51l, C59R, S108N, 1164L) and dihydropteroate synthetase (pfdhps A436S, G437A and E540K) genes and pfmdr1 gene copy numbers were determined using PCR based methods.
\end{abstract}

Results: The prevalence of pfcrt $76 \mathrm{~T}$ and pfmdr $186 \mathrm{Y}$ was $93 \%$ and $57 \%$, respectively. The prevalence of pfdhfr double mutations $59 \mathrm{R}+108 \mathrm{~N} / 51 \mathrm{R}+108 \mathrm{~N}$ was $92 \%$. The pfdhfr triple mutation $(51 \mathrm{l}, 59 \mathrm{R}, 108 \mathrm{~N})$ occurred in $3 \%$ of samples. The pfdhfr (51I, 59R, 108N) and pfdhps (437G, 540E) quintuple mutation was found in one isolate. Pfdhps $437 \mathrm{G}$ was observed in 51\% and 540E in 1\% of the isolates. One isolate had two pfmdr1 copies and carried the pfmdr1 86Y and pfcrt 76T alleles.

Conclusions: The results indicate high prevalence of in vivo resistance to chloroquine, whereas high grade resistance to sulphadoxine-pyrimethamine does not appear to be widespread among $P$. falciparum in southern Pakistan.

\section{Background}

Development and spread of Plasmodium falciparum resistance to anti-malarial drugs represents a major threat to global malaria control. In Pakistan, an estimated 500,000 episodes of malaria infection occur annually [1]. The incidence of malaria has markedly increased during the last decade and the relative frequency of $P$. falciparum amongst blood-slide positive malaria infections has increased from $45 \%$ in 1995 to $68 \%$ in 2006 [2-4], probably due to increasing resistance to commonly used monotherapies.

\footnotetext{
* Correspondence: johan.ursing@karolinska.se

† Contributed equally

${ }^{2}$ Malaria Research Lab, Infectious Diseases Unit, Department of Medicine, Karolinska University Hospital/Karolinska Institutet, Retziusväg 10, 17177

Stockholm, Sweden

Full list of author information is available at the end of the article
}

Chloroquine resistance was first reported from Pakistan in 1984 and was followed by several reports confirming it in Punjab, Afghan refugee camps and areas bordering Afghanistan [5-8]. In agreement with recommendations by the World Health Organization, Pakistan has adopted artemisinin-based combination therapy (ACT) as treatment of choice for uncomplicated $P$. falciparum malaria with artesunate plus sulphadoxine-pyrimethamine as first-line treatment [9]. However, the use of this combination is of some concern as resistance to sulphadoxine-pyrimethamine monotherapy has been reported from western Pakistan [10].

Analyses of molecular markers associated with $P$. falciparum anti-malarial drug resistance can provide important information about levels of sulphadoxinepyrimethamine resistance. Single nucleotide polymorphisms (SNPs) at codons 51, 59, 108 and 164 in the $P$. falciparum dihydrofolate reductase gene (pfdhfr) are

\section{Biomed Central}


well established determinants of pyrimethamine resistance [11]. An initial mutation at codon 108 causes 7-50 fold increase in the in vitro inhibitory concentration (IC50). The presence of additional mutations further increase IC50 and the triple mutant (N51I/C59R/ S108N) is associated with clinical treatment failure [12,13]. Similarly, mutations at codons 436, 437, 540, 581 and 613 in the P. falciparum dihydroptereoate synthase gene (pfdhps) are associated with sulphadoxine resistance $[14,15]$.

Other genetic polymorphisms have also been associated with $P$. falciparum drug tolerance/resistance. The K76 T amino acid substitution in the chloroquine resistance transporter gene ( $p f c r t$ ) has been shown to be essential for chloroquine resistance, associated with amodiaquine resistance and predictive of treatment failure for both drugs [16,17]. Pfcrt 76K has been associated with lumefantrine tolerance/resistance and higher IC50 values [18-20]. The $P$. falciparum multidrug resistance gene 1 (pfmdr1) allele 86Y has been associated with chloroquine and amodiaquine resistance and increased chloroquine IC50 values in $P$. falciparum with pfcrt $76 \mathrm{~T}[21,22]$. In a meta analysis $p f m d r 186 \mathrm{Y}$ was significantly linked to chloroquine and amodiaquine resistance [23]. Conversely, $p f m d r 186 \mathrm{~N}$ has been associated with lumefantrine tolerance/resistance and higher lumefantrine IC50 [20,24,25]. Pfmdr1 amplifications are associated with mefloquine resistance in vivo and in vitro, doubled lumefantrine IC50 and reduced sensitivity to artesunate [26].

Scarce data are available on anti-malarial drug resistance among the P. falciparum population in Pakistan. The aim of this study was, therefore, to assess the prevalence of $P$. falciparum resistance associated polymorphisms in field isolates from southern Pakistan.

\section{Methods}

\section{Study setting, participants and ethics}

The study was conducted between October 2005 and October 2007 at the Aga Khan University Hospital, a tertiary hospital located in central Karachi, and its established chain of primary health care and diagnostic service centres located in Sindh and Baluchistan provinces, Pakistan. In the study area, malaria transmission peaks during and after the monsoon season that lasts from June to October. Patients with microscopy confirmed $P$. falciparum mono-infection were eligible for enrolment irrespective of age, sex and disease severity.

The study was conducted in accordance with the Declaration of Helsinki and Good Clinical Practice [27]. Informed consent was obtained from all participants or in case of children from their parents/legal guardians. The study was approved by the ethical review committee of Aga Khan University Hospital, Karachi, Pakistan.

\section{Blood collection and microscopy}

Two $\mathrm{ml}$ of intravenous blood were collected in an EDTA tube from all patients referred to the laboratory for investigation of malaria infection. For screening purposes a thick blood film was prepared and analysed using Leishman stain according to routine practice. In case of a positive screening result, a thick and thin Giemsa-stained blood film was prepared for confirmation of the presence of malaria parasites and species identification. For all patients with confirmed P. falciparum mono-infection the parasite density was assessed by counting asexual parasites against 200 white blood cells (WBC) on the thick film and quantified (parasites/ $\mu \mathrm{l})$ by assuming an average of $8000 \mathrm{WBC}$ per $\mu$ l blood [28]. All blood slides were examined by experienced microscopists at the clinical laboratory of Aga Khan University Hospital. For quality control, $10 \%$ of the blood slides were re-examined by an independent microscopist unaware of the initial result.

From each sample $100 \mu \mathrm{l}$ of blood was spotted on an FTA $^{\circledR}$ filter paper (Whatman), dried, then put in a separate plastic bag and stored at $-80^{\circ} \mathrm{C}$. The remaining blood was transferred to cryo-vials and kept frozen at $-80^{\circ} \mathrm{C}$ until used for DNA extraction. A brief epidemiological and demographic history was also collected from each participant using a structured questionnaire.

\section{DNA extraction}

DNA was extracted using Qiamp DNA mini Kits (Qiagen, USA) from $200 \mu \mathrm{l}$ of whole blood at Aga Khan University Hospital. The FTA ${ }^{\circledR}$ filter papers were transported to Karolinska Institutet, where DNA was extracted from approximately half of each blood sample $(50 \mu \mathrm{l})$ using an ABI Prism ${ }^{\circledR} 6100$ Nucleic Acid Prep Station (Applied Biosystems, Fresno, CA). In both cases DNA extraction was according to the manufacturer's instructions. Extracted DNA was stored at $-20^{\circ} \mathrm{C}$ until amplified by PCR.

\section{Genotyping}

Pfcrt K76T and pfmdr1 N86Y alleles were analysed for all samples at Aga Khan University Hospital. Quality control was done at Karolinska Institutet by genotyping a randomly selected subset of $25 \%$ of the samples. The same multiplex PCR-RFLP protocol [29] was used at both laboratories.

SNPs at pfdhfr codons 16, 51, 59, 108 and 164, and pfdhps codons 436,437 and 540 were identified by sequencing according to a previously described method [30]. The PCRs were performed at Karolinska Institutet. The products were purified and sequenced commercially (Macrogen Inc. Seoul, Korea). For quality control, the genotype at codon 540 was determined from $25 \%$ of the samples using a PCR-RFLP based method [29]. Codon 
540 was chosen because of its location towards the end of the amplified segment, where sequencing is less robust. PCR and restriction products were resolved on 2\% agarose gels (Amresco, Solon, OH). All gels were stained with ethidium bromide and visualized under UV transillumination (GelDoc ${ }^{\circledR}$, Biorad, Hercules, Ca, USA).

$P f m d r 1$ gene copy number variation polymorphism was determined using real time PCR (ABI Prism ${ }^{\circledR} 7000$ Sequence Detection System) as previously described [26]. All samples were run in triplicate. The clones, 3D7, D10 and K1 were used as single copy calibrators and FCB and Dd2 represented multiple copy controls. Pfmdr1 copy numbers were calculated using a comparative threshold method ( $\Delta \Delta \mathrm{C}_{\mathrm{t}}$ method) [26]. An amplification of $p f m d r 1$ was defined as copy number $>1.6$. Assays were repeated if the following results were obtained: copy number 1.3-1.6 or $\mathrm{Ct}$ value $>35$ or $\Delta \Delta \mathrm{C}_{\mathrm{t}}$ spread $>1.5$.

\section{Power calculation and statistical analyses}

This was a descriptive/exploratory study precluding a power calculation of sample size. Data were entered, validated and analysed using SPSS version 16.0. The Sequencher TM software version 4.6 (Gene Codes Corporation, Ann Arbor, MI) was used to analyse the sequences output using the 3D7 clone sequence obtained from NCBI database ( $p f d h f r$ Accession \# JO4643 and pfdhps XM_001349382) as a reference. Allele proportions were calculated as the number carrying a certain allele divided by the number of samples with positive PCR outcome. Mixed infections thus contribute to the prevalence of both alleles.

\section{Results}

\section{Patients}

A total of 244 patients with microscopy confirmed $P$. falciparum mono-infection were enrolled. Baseline demographic data are presented in Table 1.
Table 2 Prevalence of pfcrt 76K, 76T, pfmdr1 86N and $86 \mathrm{Y}$ alleles in southern Pakistan

\begin{tabular}{lccccccc}
\hline & \multicolumn{3}{c}{ Pfcrt } & \multicolumn{3}{c}{ Pfmdr 1 } \\
\cline { 2 - 8 } & $\mathbf{n}$ & $\mathbf{7 6 K}$ & $\mathbf{7 6 T}$ & $\mathbf{7 6 T / K}$ & $\mathbf{8 6 N}$ & $\mathbf{8 6 Y}$ & $\mathbf{8 6 Y / N}$ \\
\hline Karachi & 178 & 16 & 161 & 1 & 73 & 84 & 21 \\
& & $(0.09)$ & $(0.91)$ & $(0.006)$ & $(0.41)$ & $(0.47)$ & $(0.12)$ \\
Sindh & 52 & 0 & $52(1)$ & 0 & 25 & 20 & 7 \\
& & & & & $(0.48)$ & $(0.39)$ & $(0.14)$ \\
Baluchistan & 10 & 1 & $9(0.90)$ & 0 & $6(0.60)$ & $4(0.40)$ & 0 \\
& & $(0.10)$ & & & & & \\
Total & 240 & 17 & 222 & 1 & 104 & 108 & 28 \\
& & $(0.07)$ & $(0.93)$ & $(0.004)$ & $(0.43)$ & $(0.45)$ & $(0.12)$ \\
\hline
\end{tabular}

Allele proportions are shown in brackets.

\section{Pfcrt and pfmdr1 SNPs}

Pfcrt K76T and pfmdr 1 N86Y were successfully amplified in 240/244 (98\%) samples. Allele proportions are presented in Table 2. Pfcrt 76T and pfmdr1 $86 \mathrm{Y}$ occurred together in 127/240 (53\%) patients. Pfcrt 76T and pfmdr1 $86 \mathrm{~N}$ were observed in $96 / 240$ (40\%) of patients. Pfcrt $76 \mathrm{~K}$ and pfmdr $186 \mathrm{~N}$ were found together in $8 / 240$ (3\%). PCR amplification failed repeatedly in $4 / 244$ (2\%) samples. For that reason these samples were excluded from further PCR analyses ( $p f m d r 1$ copy number, $p f d h f r$ and $p f d h p s$ )

\section{Pfmdr1 copy number}

The real-time PCR was successful in 232/240 (97\%) samples. A single pfmdr1 gene was found in 231 samples. One sample had 2 copies of the $p f m d r 1$ gene and carried the pfmdr1 86Y and pfcrt 76T alleles.

\section{Pfdhfr and pfdhps}

PCR amplifications and sequencing of pfdhfr and $p f d h p s$ were successful in 218/240 (91\%) and 231/240 (96\%) samples, respectively. The prevalence of SNPs at codon 51, 59 and 108 of $p f d h f r$ and codon 436, 437 and 540 of pfdhps are presented in Table 3. The pfdhfr alleles $108 \mathrm{~T}, 16 \mathrm{~V}$ and $164 \mathrm{~L}$ were not observed.

Table 1 Baseline characteristics of enrolled patients

\begin{tabular}{|c|c|c|c|c|}
\hline & $\begin{array}{c}\text { All } \\
(n=244)\end{array}$ & $\begin{array}{c}\text { Karachi } \\
(n=182)\end{array}$ & $\begin{array}{c}\text { Sindh } \\
(n=52)\end{array}$ & $\begin{array}{l}\text { Baluchistan } \\
\quad(n=10)\end{array}$ \\
\hline \multicolumn{5}{|l|}{ Age * } \\
\hline$\leq 5$ years & $35(0.14)$ & $16(0.09)$ & $17(0.33)$ & $2(0.20)$ \\
\hline 6-15 years & $39(0.16)$ & $26(0.14)$ & $12(0.23)$ & $1(0.10)$ \\
\hline$>15$ years & $170(0.70)$ & $140(0.77)$ & $23(0.44)$ & $7(0.70)$ \\
\hline \multicolumn{5}{|l|}{ Sex* } \\
\hline Male & $173(0.71)$ & $137(0.75)$ & $31(0.60)$ & $5(0.50)$ \\
\hline Female & $71(0.29)$ & $45(0.25)$ & $21(0.40)$ & $5(0.50)$ \\
\hline Parasite density ${ }^{\S}$ (parasites/ $\mu \mathrm{l}$ ) & $11100(80-540000)$ & $12720(80-540000)$ & $7480(80-126000)$ & $66160(240-230220)$ \\
\hline Gametocyte carriage & $96(0.45)$ & $69(0.43)$ & $23(0.48)$ & $4(0.45)$ \\
\hline
\end{tabular}

* Number of patients are presented with proportions in brackets.

$\S$ Parasite densities were available form 216 patients. Median data are presented with range in brackets. 
Table 3 Prevalence of resistance associated single nucleotide polymorphisms in pfdhfr and pfdhps from southern Pakistan

\begin{tabular}{lcccccccc}
\hline & \multicolumn{3}{c}{ Pfdhfr } & \multicolumn{3}{c}{ Pfdhps } \\
\cline { 2 - 8 } & $\mathbf{n}$ & $\mathbf{5 1 1}$ & $\mathbf{5 9 R}$ & $\mathbf{1 0 8 N}$ & $\mathbf{n}$ & 436A & 437G & 540E \\
\hline Karachi & 161 & $16(0.1)$ & $144(0.89)$ & $159(0.99)$ & 170 & $1(0.006)$ & $99(0.58)$ & $3(0.02)$ \\
Sindh & 48 & $2(0.04)$ & $44(0.92)$ & $47(0.98)$ & 51 & 0 & $13(0.26)$ & 0 \\
Baluchistan & 9 & 0 & $9(1)$ & $9(1)$ & 10 & 0 & $6(0.60)$ & 0 \\
Total & 218 & $18(0.08)^{*}$ & $197(0.90)^{\S}$ & $215(0.99)$ & 231 & $1(0.004)$ & $118(0.51)$ & $3(0.01)^{\dagger}$ \\
\hline
\end{tabular}

Allele proportions are shown in brackets. Pfdhfr alleles $108 \mathrm{~T}, 16 \mathrm{~V}$ and $164 \mathrm{~L}$ were not observed.

* 3/218 had mix infection with pfdhfr $51 \mathrm{l}$ and $51 \mathrm{~N}$ alleles, ${ }^{\S} 5 / 218$ had mix infection with pfdhfr $59 \mathrm{C}$ and $59 \mathrm{R}$ alleles.

+ $2 / 231$ had mix infection with pfdhps 540E and 540K allele.

The pfdhfr double mutation $59 \mathrm{R}+108 \mathrm{~N}$ was found in $190 / 218(87 \%)$ and $51 \mathrm{I}+108 \mathrm{~N}$ was found in $11 / 218$ (5\%) samples. The prevalence of pfdhfr double mutations $51 \mathrm{I}+108 \mathrm{~N} / 59 \mathrm{R}+108$ was $201 / 218(92 \%)$. The pfdhfr triple mutation (51I, 59R, 108N) occurred in $7 /$ 218 (3\%) samples. The above mentioned $p f d h f r$ triple mutation haplotype was found together with $p f d h p s$ 437G in one sample. The combined pfdhfr (51I, 59R, $108 \mathrm{~N}$ ) and pfdhps (437G, 540E) quintuple mutation was found in one isolate from Karachi. The pfdhfr 51, 59, 108,164 and pfdhps 436, 437 and 540 haplotypes are presented in Table 4. Thirteen different pfdhfr-pfdhps haplotypes were identified.

\section{Discussion}

This is the most comprehensive report characterizing resistance associated genetic polymorphisms in P. falciparum field samples collected in southern Pakistan. As such, the results bridge an important knowledge gap of the P. falciparum population in South Asia.
The 93\% prevalence of pfcrt 76T, essential for chloroquine resistance, is in line with results from neighbouring countries $[16,31,32]$. This data indicate high levels of in vivo P. falciparum chloroquine resistance in southern Pakistan. Moreover, the high pfcrt 76T and moderately high (57\%) pfmdr1 86Y prevalence also suggests high levels of tolerance/resistance to amodiaquine in the study area.

The high prevalence of the pfdhfr $108 \mathrm{~N}$ (99\%) and 51I $+108 \mathrm{~N} / 59 \mathrm{R}+108 \mathrm{~N}(92 \%)$ in our study indicate that decreased susceptibility to sulphadoxine-pyrimethamine is widespread in Pakistan. However, only seven patients had infections with the triple pfdhfr resistance associated haplotype and only one patient was infected with $P$. falciparum that had the quintuple $p f d h f r+p f d h p s$ haplotype associated with high grade sulphadoxine-pyrimethamine resistance. These results indicate that high grade resistance to sulphadoxine-pyrimethamine is not widespread and suggest that this drug is probably suitable for use with artesunate in southern Pakistan, as recommended by the National Malaria Control

Table 4 Prevalence of pfdhfr- pfdhps haplotypes in P. falciparum isolates from southern Pakistan

\begin{tabular}{|c|c|c|c|c|c|}
\hline \multirow{2}{*}{$\begin{array}{l}\text { Pfdhfr N51I, C59R, S108N, I164L } \\
\text { Pfdhps S436A, A437G, K540E* }\end{array}$} & \multirow[b]{2}{*}{$\begin{array}{l}\text { No. of } \\
\text { mutations }\end{array}$} & \multicolumn{4}{|c|}{ No. of isolates } \\
\hline & & $\begin{array}{c}\text { Karachi } \\
(n=158)\end{array}$ & $\begin{array}{l}\text { Sindh } \\
(n=47)\end{array}$ & $\begin{array}{l}\text { Baluchistan } \\
\quad(n=9)\end{array}$ & $\begin{array}{c}\text { Total } \\
(n=214)\end{array}$ \\
\hline NCSI-SAK & 0 & - & $1(0.02)$ & - & $1(0.005)$ \\
\hline NRNI-SGK & 3 & $80(0.51)$ & $9(0.19)$ & $5(0.55)$ & $94(0.44)$ \\
\hline NRNI-SAK & 2 & $55(0.35)$ & $33(0.70)$ & $4(0.45)$ & $92(0.43)$ \\
\hline IRNI-SGK & 4 & $1(0.006)$ & - & - & $1(0.005)$ \\
\hline IRNI-SGE & 5 & $1(0.006)$ & - & - & $1(0.005)$ \\
\hline IRNI-SAK & 3 & $4(0.03)$ & $1(0.02)$ & - & $5(0.02)$ \\
\hline ICNI-SAK & 2 & $5(0.03)$ & - & - & $5(0.02)$ \\
\hline ICNI-SGK & 3 & $3(0.02)$ & $1(0.02)$ & - & $4(0.02)$ \\
\hline ICNI-SGE & 4 & $2(0.01)$ & - & - & $2(0.01)$ \\
\hline NCNI-SAK & 1 & $3(0.02)$ & - & - & $3(0.01)$ \\
\hline NCNI-SGK & 2 & $2(0.01)$ & $2(0.04)$ & - & $4(0.02)$ \\
\hline NCSI-AAK & 1 & $1(0.006)$ & - & - & $1(0.005)$ \\
\hline NCSI-SGK & 1 & $1(0.006)$ & - & - & $1(0.005)$ \\
\hline
\end{tabular}

pfdhfr-pfdhps haplotypes proportions are shown in brackets.

* Resistance associated alleles are indicated in bold. 
Programme. However, the occurrence of triple and quintuple mutant $P$. falciparum is of concern as widespread use of sulphadoxine-pyrimethamine as a partner to artesunate may rapidly select these haplotypes. Monitoring of $p f d h f r$ and $p f d h p s$ resistance associated haplotypes is consequently of importance. Furthermore, artesunate + sulphadoxine-pyrimethamine in vivo efficacy urgently needs to be assessed. This is critical as efficacy studies conducted in Baluchistan (2001-2005) reported $56 \%$ treatment failure with sulphadoxine-pyrimethamine monotherapy [33]

Only one patient had a $P$. falciparum infection with two copies of $p f m d r 1$, a finding that should be interpreted with caution. Increased $p f m d r 1$ copy number has been associated with an increased risk for treatment failure after mefloquine monotherapy and artesunatemefloquine therapy [26]. The low prevalence of $p f m d r 1$ amplifications observed in this study suggests that both artesunate-mefloquine and artemether-lumefantrine would be efficacious in southern Pakistan. They may therefore represent potential future treatment alternatives to artesunate + sulphadoxine-pyrimethamine. Furthermore, the observed low prevalence of $p f c r t 76 \mathrm{~K}$ and $p f m d r 186 \mathrm{~N}$ provides supporting evidence of a probable high artemether-lumefantrine efficacy $[20,24]$

This data concur with recent results from a small study $(\mathrm{n}=28)$ conducted in Khyber Pkhtunkhwan Province, Pakistan and previous data from India and Iran [34]. Furthermore, just as in northern India and Iran the pfdhfr $\mathrm{A}_{16} \mathrm{~N}_{51} \mathbf{R}_{59} \mathbf{N}_{108} \mathrm{I}_{164}$ and $\mathrm{A}_{16} \mathbf{I}_{51} \mathbf{R}_{59} \mathbf{N}_{108} \mathrm{I}_{164}$ were the most common double and triple mutants found $[35,36]$. These results thus support a selective sweep of chloroquine and sulphadoxine-pyrimethamine resistant P. falciparum from southeast Asia via India to Pakistan and then on to Iran [37-40]

It should be underlined that a majority of patients (74\%) presented with symptomatic malaria infection at the Aga Khan University Hospital that represents tertiary level of care. Some of these patients may have received anti-malarial treatment prior to enrolment in this study and the P. falciparum SNP proportions reported may, therefore, not be representative for the parasite population in southern Pakistan. However, the similarity of our results with those reported from neighbouring countries suggests that the results may be generalized.

\section{Conclusion}

The results indicate high prevalence of in vivo resistance to chloroquine among P. falciparum in southern Pakistan, but high grade resistance to sulfadoxine-pyrimethamine does not appear to be widespread in the parasite population. This data thus support the recent change of first line therapy for uncomplicated $P$. falciparum malaria from chloroquine to artesunate + sulphadoxine-pyrimethamine. Continued anti-malarial drug resistance surveillance in Pakistan is essential.

\section{Acknowledgements}

This work was supported by University Research Council grant (URC \# 051012 P\&M) by Aga Khan University (MAB). Higher Education Commission, Government of Pakistan and The Swedish institute (NKG) (Ref \# 042-130358Ls2305). The Swedish South Asian Studies Network 2005 and 2008 (AM; JU). Fundacão para a Ciência e Tecnologia, Portugal, PhD Grant (SFRH/BD/28393/ 2006) (MIV). We gratefully acknowledge Clinical Laboratory staff at Aga Khan University Hospital for providing us malaria positive samples. We also thank colleagues at the Malaria Research Laboratory, Karolinska Institutet, for support and valuable comments, and Dr. Sabina Dahlström for molecular training (NKG).

\section{Author details}

${ }^{1}$ Department of Pathology and Microbiology, Aga Khan University, Stadium Road, P.O. Box 3500, Karachi 74800, Pakistan. ${ }^{2}$ Malaria Research Lab, Infectious Diseases Unit, Department of Medicine, Karolinska University Hospital/Karolinska Institutet, Retziusväg 10, 17177 Stockholm, Sweden. ${ }^{3}$ Drug Resistance and Pharmacogenetics Group, Institute of Biotechnology and Bioengineering, Centre of Molecular and Structural Biomedicine, University of Algarve, 8500-139 Faro, Portugal. ${ }^{4}$ Division of Global Health (IHCAR), Department of Public Health Sciences, Karolinska Institutet, Nobelsväg 9, S-171 77 Stockholm, Sweden.

\section{Authors' contributions}

NKG performed DNA extractions and PCR genotyping, data entry, analysis and interpretation and drafted the first version of the report. $J U$ designed and planned the study, performed data analysis and interpretation and wrote the report. MIV and SJ participated in PCR genotyping and data analyses. MAB and AM designed and planned the study, data analysis and interpretation and wrote the report. All authors read and approved the final manuscript.

\section{Competing interests}

The authors declare that they have no competing interests.

Received: 21 October 2010 Accepted: 28 January 2011 Published: 28 January 2011

\section{References}

1. Yasinzai MI, Kakarsulemankhel JK: Prevalence of human malaria infection in bordering areas of East Balochistan, adjoining with Punjab: Loralai and Musakhel. J Pak Med Assoc 2009, 59:132-135.

2. Rab MA, Freeman TW, Durrani N, de Poerck D, Rowland MW: Resistance of Plasmodium falciparum malaria to chloroquine is widespread in eastern Afghanistan. Ann Trop Med Parasitol 2001, 95:41-46.

3. Hozhabri S, Akhtar S, Rahbar MH, Luby SP: Prevalence of Plasmodium slide positivity among the children treated for malaria, Jhangara, Sindh. J Pak Med Assoc 2000, 50:401-405.

4. Durrani AB, Durrani IU, Abbas N, Jabeen M: Epidemiology of cerebral malaria and its mortality. J Pak Med Assoc 1997, 47:213-215.

5. Rana MS, Tanveer A: Chloroquine resistance and Plasmodium falciparum in Punjab, Pakistan during 2000-2001. Southeast Asian J Trop Med Public Health 2004, 35:288-291.

6. Fox E, Khaliq AA, Sarwar M, Strickland GT: Chloroquine-resistant Plasmodium falciparum: now in Pakistani Punjab. Lancet 1985, 1:1432-1435.

7. Shah I, Rowland M, Mehmood P, Mujahid C, Razique F, Hewitt S, Durrani N: Chloroquine resistance in Pakistan and the upsurge of falciparum malaria in Pakistani and Afghan refugee populations. Ann Trop Med Parasitol 1997, 91:591-602.

8. Robinson DS, Hadley-Brown M, Ejele OA, Robinson PS: Chloroquineresistant malaria in Pakistan. Lancet 1984, 2:987.

9. WHO: World malaria report. 2008 [http://whqlibdoc.who.int/publications/ 2008/9789241563697_eng.pdf].

10. Rowland M, Durrani $\bar{N}$, Hewitt S, Sondorp E: Resistance of falciparum malaria to chloroquine and sulfadoxine-pyrimethamine in Afghan 
refugee settlements in western Pakistan: surveys by the general health services using a simplified in vivo test. Trop Med Int Health 1997, 2:1049-1056.

11. Plowe CV, Djimde A, Bouare M, Doumbo O, Wellems TE: Pyrimethamine and proguanil resistance-conferring mutations in Plasmodium falciparum dihydrofolate reductase: polymerase chain reaction methods for surveillance in Africa. Am J Trop Med Hyg 1995, 52:565-568.

12. Mendez F, Munoz A, Carrasquilla G, Jurado D, Arevalo-Herrera M, Cortese JF, Plowe CV: Determinants of treatment response to sulfadoxinepyrimethamine and subsequent transmission potential in falciparum malaria. Am J Epidemiol 2002, 156:230-238.

13. Plowe CV, Cortese JF, Djimde A, Nwanyanwu OC, Watkins WM, Winstanley PA, Estrada-Franco JG, Mollinedo RE, Avila JC, Cespedes JL, Carter D, Doumbo OK: Mutations in Plasmodium falciparum dihydrofolate reductase and dihydropteroate synthase and epidemiologic patterns of pyrimethamine-sulfadoxine use and resistance. J Infect Dis 1997, 176:1590-1596.

14. Gregson A, Plowe CV: Mechanisms of resistance of malaria parasites to antifolates. Pharmacol Rev 2005, 57:117-145.

15. Triglia $T$, Wang $P$, Sims PF, Hyde JE, Cowman AF: Allelic exchange at the endogenous genomic locus in Plasmodium falciparum proves the role of dihydropteroate synthase in sulfadoxine-resistant malaria. EMBO J 1998, 17:3807-3815.

16. Fidock DA, Nomura T, Talley AK, Cooper RA, Dzekunov SM, Ferdig MT, Ursos LM, Sidhu AB, Naude B, Deitsch KW, Su XZ, Wootton JC, Roepe PD, Wellems TE: Mutations in the $P$. falciparum digestive vacuole transmembrane protein PfCRT and evidence for their role in chloroquine resistance. Mol Cell 2000, 6:861-871.

17. Djimde A, Doumbo OK, Cortese JF, Kayentao K, Doumbo S, Diourte $Y$, Dicko A, Su XZ, Nomura T, Fidock DA, Wellems TE, Plowe CV, Coulibaly D: A molecular marker for chloroquine-resistant falciparum malaria. $N$ Engl J Med 2001, 344:257-263.

18. Sisowath C, Petersen I, Veiga MI, Martensson A, Premij Z, Bjorkman A, Fidock DA, Gil JP: In vivo selection of Plasmodium falciparum parasites carrying the chloroquine-susceptible pfcrt K76 allele after treatment with artemether-lumefantrine in Africa. J Infect Dis 2009, 199:750-757.

19. Sisowath C, Ferreira PE, Bustamante LY, Dahlstrom S, Martensson A, Bjorkman A, Krishna S, Gil JP: The role of pfmdr1 in Plasmodium falciparum tolerance to artemether-lumefantrine in Africa. Trop Med Int Health 2007, 12:736-742.

20. Mwai L, Kiara SM, Abdirahman A, Pole L, Rippert A, Diriye A, Bull P, Marsh K, Borrmann S, Nzila A: In vitro activities of piperaquine, lumefantrine, and dihydroartemisinin in Kenyan Plasmodium falciparum isolates and polymorphisms in pfcrt and pfmdr1. Antimicrob Agents Chemother 2009, 53:5069-5073.

21. Babiker HA, Pringle SJ, Abdel-Muhsin A, Mackinnon M, Hunt P, Walliker D: High-level chloroquine resistance in Sudanese isolates of Plasmodium falciparum is associated with mutations in the chloroquine resistance transporter gene pfcrt and the multidrug resistance gene pfmdr1. $J$ Infect Dis 2001, 183:1535-1538.

22. Ursing J, Kofoed PE, Rodrigues A, Rombo L, Gil JP: Plasmodium falciparum genotypes associated with chloroquine and amodiaquine resistance in Guinea-Bissau. Am J Trop Med Hyg 2007, 76:844-848.

23. Picot S, Olliaro P, de Monbrison F, Bienvenu AL, Price RN, Ringwald P: A systematic review and meta-analysis of evidence for correlation between molecular markers of parasite resistance and treatment outcome in falciparum malaria. Malar J 2009, 8:89.

24. Sisowath C, Stromberg J, Martensson A, Msellem M, Obondo C, Bjorkman A, Gil JP: In vivo selection of Plasmodium falciparum pfmdr1 $86 \mathrm{~N}$ coding alleles by artemether-lumefantrine (Coartem). J Infect Dis 2005, 191:1014-1017.

25. Duraisingh MT, Roper C, Walliker D, Warhurst DC: Increased sensitivity to the antimalarials mefloquine and artemisinin is conferred by mutations in the pfmdr1 gene of Plasmodium falciparum. Mol Microbiol 2000, 36:955-961.

26. Price RN, Uhlemann AC, Brockman A, McGready R, Ashley E, Phaipun L, Patel R, Laing K, Looareesuwan S, White NJ, Nosten F, Krishna S: Mefloquine resistance in Plasmodium falciparum and increased pfmdr1 gene copy number. Lancet 2004, 364:438-447.
27. WMA: Declaration of Helsinki: Ethical Principles for Medical Research Involving Human Subjects. 2004 [http://www.wma.net/en/30publications/ 10policies/b3/17c.pdf].

28. Moody A: Rapid diagnostic tests for malaria parasites. Clin Microbiol Rev 2002, 15:66-78.

29. Veiga MI, Ferreira PE, Bjorkman A, Gil JP: Multiplex PCR-RFLP methods for pfcrt, pfmdr1 and pfdhfr mutations in Plasmodium falciparum. Mol Cell Probes 2006, 20:100-104.

30. Ndiaye D, Daily JP, Sarr O, Ndir O, Gaye O, Mboup S, Wirth DF: Mutations in Plasmodium falciparum dihydrofolate reductase and dihydropteroate synthase genes in Senegal. Trop Med Int Health 2005, 10:1176-1179.

31. Ursing J, Zakeri S, Gil JP, Bjorkman A: Quinoline resistance associated polymorphisms in the pfcrt, pfmdr1 and pfmrp genes of Plasmodium falciparum in Iran. Acta Trop 2006, 97:352-356.

32. Vinayak S, Biswas S, Dev V, Kumar A, Ansari MA, Sharma YD: Prevalence of the K76T mutation in the pfcrt gene of Plasmodium falciparum among chloroquine responders in India. Acta Trop 2003, 87:287-293.

33. WHO: Division of communicable disease control newsletter. 2005, 6:1-4.

34. Khatoon L, Baliraine FN, Bonizzoni M, Malik SA, Yan G: Prevalence of antimalarial drug resistance mutations in Plasmodium vivax and $P$. falciparum from a malaria-endemic area of Pakistan. Am J Trop Med Hyg 2009, 81:525-528.

35. Ahmed A, Bararia D, Vinayak S, Yameen M, Biswas S, Dev V, Kumar A, Ansari MA, Sharma YD: Plasmodium falciparum isolates in India exhibit a progressive increase in mutations associated with sulfadoxinepyrimethamine resistance. Antimicrob Agents Chemother 2004, 48:879-889

36. Zakeri S, Afsharpad M, Raeisi A, Djadid ND: Prevalence of mutations associated with antimalarial drugs in Plasmodium falciparum isolates prior to the introduction of sulphadoxine-pyrimethamine as first-line treatment in Iran. Malar J 2007, 6:148.

37. Nair S, Williams JT, Brockman A, Paiphun L, Mayxay M, Newton PN, Guthmann JP, Smithuis FM, Hien TT, White NJ, Nosten F, Anderson TJ: A selective sweep driven by pyrimethamine treatment in southeast asian malaria parasites. Mol Biol Evol 2003, 20:1526-1536.

38. Roper C, Pearce R, Bredenkamp B, Gumede J, Drakeley C, Mosha F, Chandramohan D, Sharp B: Antifolate antimalarial resistance in southeast Africa: a population-based analysis. Lancet 2003, 361:1174-1181.

39. Lumb V, Das MK, Singh N, Dev V, Wajihullah, Sharma YD: Characteristics of genetic hitchhiking around dihydrofolate reductase gene associated with pyrimethamine resistance in Plasmodium falciparum isolates from India. Antimicrob Agents Chemother 2009, 53:5173-5180.

40. Mita T: Origins and spread of pfdhfr mutant alleles in Plasmodium falciparum. Acta Trop 2009, 114:166-170.

doi:10.1186/1475-2875-10-18

Cite this article as: Ghanchi et al:: Prevalence of resistance associated polymorphisms in Plasmodium falciparum field isolates from southern Pakistan. Malaria Journal 2011 10:18.

\section{Submit your next manuscript to BioMed Central and take full advantage of:}

- Convenient online submission

- Thorough peer review

- No space constraints or color figure charges

- Immediate publication on acceptance

- Inclusion in PubMed, CAS, Scopus and Google Scholar

- Research which is freely available for redistribution

Submit your manuscript at www.biomedcentral.com/submit
C Biomed Central 